\title{
Complementary therapies for cancer patients: assessing information use and needs
}

\author{
MJ Verhoef, PhD (1); L Trojan, BSc (2); GD Armitage, MA (2); L Carlson, PhD (3); RJ Hilsden, PhD (1)
}

\begin{abstract}
Many cancer patients seek complementary therapies (CTs) for cancer management; however, relatively little is known about patients' CT information seeking behaviour. Therefore, we assessed: 1) cancer patients' use of the types and sources of CT information; 2) their information preferences; and 3) their understanding of the phrase "scientific evidence or proof that a therapy works." We collected data from 404 patients attending the Tom Baker Cancer Centre (TBCC) in Calgary and 303 patients calling the Cancer Information Service (CIS) helpline. In most cases, patients wanted information on the safety of CTs, how CTs work and their potential side effects. Physicians and conventional cancer centres were the most desired sources of CT information, but relatively few patients obtained information via these sources. Although patients were aware of the meaning of scientific evidence, they often used information based on non-scientific evidence, such as patient testimonials. The creation of a supportive care environment in conventional cancer treatment centres, by providing CT information, may help address cancer patients' concerns and alleviate some of the stress that may have been caused by the cancer diagnosis.
\end{abstract}

Keywords: CAM, cancer, alternative therapies, complementary therapies, information use and needs, helpline

\section{Introduction}

Complementary therapies (CTs), sometimes referred to as complementary and alternative medicine (CAM), consist of a "group of diverse medical and health care systems, practices and products that are not presently considered part of conventional medicine." Studies assessing the extent of CT use among cancer patients estimate that $7 \%$ to $91 \%$ of cancer patients report using some form of complementary therapy. ${ }^{2-8}$ Although there has been an increase in research to ascertain the safety and effectiveness of CTs, mostly with respect to symptom control, ${ }^{9,10}$ the use of CTs still outpaces the evidence.
To date, most research has focused on information needs regarding conventional cancer treatments. A recent, systematic review of cancer patients' information needs and sources ${ }^{11}$ identified that patients most frequently seek treatment-related information, such as treatment options and side effects, and that patients tend to consult a wide range of sources, including health care providers, other cancer patients, friends and family members, print material, telephone helplines and the Internet. ${ }^{12-14}$ It appears that cancer patients seek sensitive information from telephone helplines and choose Web sites for basic and less sensitive information..$^{15}$ Although many patients access the Internet, ${ }^{16}$ dependence on Web sites for health information can be problematic, particularly as it relates to CTs. Furthermore, even though the quality of some Web sites is excellent, others lack information regarding the safety or efficacy of CTs, ${ }^{17}$ and may report misinformation, or conflicting or inconsistent information. ${ }^{17-19}$ Consequently, there is the potential for harm if such advice is followed, ${ }^{17,19}$ thus placing users at risk.

Cancer patients seek CT information in part because they are interested in an alternative to conventional medicine. ${ }^{20} \mathrm{CTs}$ provide patients with a holistic treatment approach and give them a sense of hope $\mathrm{e}^{20-21}$ or control:22 however, they often become frustrated with the overwhelming amount of CT information and are unsure of what information is credible. ${ }^{20}$ Despite the important role that information appears to play in cancer management, ${ }^{11}$ relatively little is known about CT information seeking behaviour, such as what information patients consider credible and which information sources they trust. Therefore, we conducted a study to assess: 1) the types and sources of CT information that cancer patients use; 2) the information they prefer; and 3) the meaning of the phrase, "scientific evidence or proof that a therapy works" to them. The results of this study will be of interest to both cancer patients who desire information on CTs and those who treat or provide care to patients interested in CT use.

Author References

1 Departments of Community Health Sciences and Medicine, University of Calgary, Calgary, Alberta, Canada

2 Health Systems and Workforce Research Unit, Calgary Health Region, Calgary, Alberta, Canada

3 Departments of Oncology and Psychology, University of Calgary, Calgary, Alberta, Canada

Correspondence: Dr. Marja J. Verhoef, Department of Community Health Sciences, University of Calgary, 3330 Hospital Drive NW, Calgary, AB T2N 4N1,

Tel.:403-220-7813, Fax: 403-270-7307 


\section{Methods}

\section{Sampling}

Participants were recruited in 2004 from two settings, the TBCC in Calgary, Alberta, Canada; and the Canadian Cancer Society's Canada-wide telephone helpline, the CIS. This sampling approach ${ }^{23}$ was chosen to focus on a range of individuals diagnosed with cancer. It allows a comparison of CT use and information seeking between people in two very different contexts. The first was a consecutive sample of new and follow-up adult cancer patients attending the TBCC outpatient clinic who were approached by a research assistant in the clinic waiting areas. The second was a consecutive sample of cancer patients calling the CIS telephone helpline who were recruited by telephone information specialists.

\section{Data collection}

Data were collected by means of a pretested, structured questionnaire developed specifically for this study. The questionnaire included basic demographic information, information about the respondent's type of cancer, diagnosis and treatment history, and questions regarding their use of and their search for information about CTs. Most questions had a yes/no, multiple choice or Likert scale response format. Respondents were also encouraged to provide additional comments about CT use for cancer. The questionnaire was pretested in a sample of 20 cancer patients at the TBCC to assess clarity and face-validity of the questions, as well as the recruitment strategy. Interested participants at the TBCC provided consent and completed the questionnaire on-site. Completion of the survey took approximately 10 minutes and most were completed before attending the scheduled clinic appointment. When requested by the participant, assistance was provided in reading and completing the questionnaire. CIS helpline callers who agreed to participate were mailed a questionnaire with a postage-paid return envelope. Follow-up telephone calls were made to those who had not returned the questionnaire within three weeks. A second questionnaire was mailed if the telephone follow-up was unsuccessful.

\section{Data analysis}

Descriptive data analysis was performed (i.e. frequency tables, percentages and means) and contingency analyses (i.e. chi-square or t-tests) were used to assess associations between socio-demographic variables, CT use and CT information seeking characteristics using SPSS data analysis software. Respondents' written comments and suggestions were analyzed using descriptive qualitative analysis. ${ }^{24}$

The study was approved by the Conjoint Health Research Ethics Board at the University of Calgary.

\section{Results}

Although some demographic and disease characteristics of the two samples (i.e. TBCC and CIS) were different, data on information needs and information seeking were fairly similar. When TBCC and CIS data are significantly different, separate analyses will be presented.

\section{TBCC participants}

Four hundred and eighty-four cancer patients in the TBCC Outpatient Clinic were invited to participate in the survey and 404 patients (i.e. 84\%) completed it. Most (i.e. 76.6\%) survey participants were visiting the TBCC for a follow-up appointment, while others were visiting for a first-time appointment (i.e. 14.1\%) or for treatment (i.e. 5.8\%). Reasons for not participating included "no time," "too stressed," “anxious” or "overwhelmed."

\section{CIS participants}

There were 572 cancer patients who called the CIS telephone helpline that were invited to participate; of these, 394 (i.e. $68.9 \%$ ) agreed to receive a questionnaire by mail. Of the 388 patients who received the questionnaire, 303 (i.e. $78.0 \%$ ) returned a completed questionnaire. This included 12 (i.e. 4\%) participants who completed the survey during the telephone follow-up. Reasons for not participating were very similar to those provided by TBCC participants, except for "recently diagnosed," which was more common in the CIS sample. Six questionnaires (i.e.
$1.5 \%$ ) were returned with an incorrect mailing address. Overall, the CIS response rate was $54 \%$.

\section{Qualitative analysis}

Respondents who voluntarily provided written comments and feedback included 137 from the CIS (i.e. $45.2 \%$ ) and 24 (i.e. $5.9 \%)$ from the TBCC. The majority of the comments expanded on the response choices provided in the survey questions and centred around three areas, i.e. barriers to finding CT information, the need for specific "evidence" and specific CT information needs. Respondents' comments will be used to illustrate the results of the quantitative analysis.

\section{Demographic and disease characteristics}

Table 1 shows demographic and disease treatment characteristics of the TBCC and CIS study participants. Gender, age distribution, years since first diagnosis, types of cancer (i.e. breast and genitourinary) and cancer treatment history (i.e. surgery, chemotherapy and hormone therapy) were significantly different between the groups $(p<0.05)$; however, in both the TBCC and CIS samples, the three most common cancers were breast, colorectal and genitourinary (mostly consisting of prostate cancer). The high proportion of females among CIS callers has been previously reported ${ }^{25}$ and may explain the higher percentage of respondents with breast cancer in the CIS sample. About $11 \%$ of TBCC and CIS respondents (i.e. $11.4 \%$ and $10.9 \%$, respectively) reported multiple cancers. This appears rather high; however, in this category, respondents had also included metastases. The data show that CIS participants were diagnosed with cancer more recently than TBCC participants.

\section{CT use}

In the questionnaire, CTs were described as "herbs, mental imagery, meditation, yoga, naturopathy, chiropractic and many others. These therapies are different than conventional cancer treatments such as surgery, radiation, chemotherapy and/ or hormone therapy and are usually not prescribed by physicians." Table 2 reports data on CT use before and after diagnosis 
by each group (i.e. TBCC and CIS). Whereas CT use among CIS patients increased little after the cancer diagnosis, it increased substantially among TBCC patients. In both samples, however, previous CT use appeared to be a strong predictor of CT use after diagnosis (i.e. $p<0.001$ for both samples). In both samples, females were significantly more likely to use CT than males (i.e. $p=0.006$ in the TBCC sample and $p=0.012$ in the CIS sample). Age was only related to CT use in the ТВCC group: patients aged 50 or younger were more likely to use CTs than those over age 50 (i.e. $p=0.008$ ). Types of CTs were grouped into nine categories and are listed in Table 3. Significant differences in CT use between the two groups were only found for herbs and supplements and special diets. Respondents were asked to check all reasons for using $\mathrm{CT}$ treatments that applied to them. Although in a different order, the three most important reasons for CT use in both groups were to improve health, strengthen the immune system, and enhance well-being and quality of life (Table 4). CIS respondents mentioned "to enhance well-being" and "to cure cancer" significantly more than TBCC respondents.

\section{CT information seeking}

Among the proportion of the 256 (i.e. $36.8 \%$ ) respondents who had sought CT information, there was a marginal difference between the two groups, i.e. $35.9 \%$ for TBCC respondents and $38.0 \%$ for CIS respondents). Table 5 shows the variation in information seeking in the two samples by sex, age and previous CT use. Although the proportion seeking information differed significantly by all three variables in the CIS sample, it was only significantly different for previous CT use in the TBCC sample. Respondents who found the information they needed differed significantly between the two samples $(p=0.027)$. In the TBCC sample, $44.6 \%$ of respondents found most of the information they needed compared to $31.5 \%$ in the CIS group; $38.8 \%$ in the TBCC group versus $55.9 \%$ found some of the information they needed; and $16.5 \%$ in the TBCC group compared to $12.6 \%$ in the CIS group did not find what they wanted. Of the information seekers who did not find all the information they needed $(\mathrm{n}=$ 118), $43.2 \%$ indicated that the available information was too general. It was too limited for $39.0 \%$, confusing for $28.8 \%$, overwhelming for $24.4 \%$ and contradictory for $23.7 \%$. The only category in which the two groups differed significantly, i.e. $33.3 \%$ in the TBCC group and $14.5 \%$ in the CIS sample, was the information made false promises. Respondents checked all that applied for this question.

In the written comments, many respondents talked about barriers to finding information. For example, "Cancer patients can't give up [looking for information]. Sometimes doctors wait too long to do treatments; patients need to find other options. It's too bad that many patients don't know about other options (treatments or resources) available to them ... you can't stop." For those who found information, they also had difficulty trusting the information: "When you are diagnosed, people literally come out of the woodwork with statements like, 'I know a rural GP or an alternative centre who are regularly curing cancer.' How on earth is a lay person supposed to be able to determine the credibility of such claims?" Another asked, "Is there a unified source of credible information available that consults scientists, oncologists, GPs and 'alternative' practitioners and provides intelligent conclusions?"

As identified in the survey, conflicting information and the sometimesoverwhelming volume of information was a challenge. "It seems to me one group says one thing and another comes along and says just the opposite. I think I would like some straight answers I could really trust."

\section{Preferred types of CT information}

Respondents were asked what three types of CT information (i.e. out of a list of 8) were most important to them; several respondents identified more than three. Among those who sought information $(\mathrm{n}=$ 256), $71.5 \%$ considered the most important information to be the safety of the therapy; $67.2 \%$, an explanation of how the therapy works; $62.8 \%$, the potential side effects of the therapy; and $62.4 \%$, proof that the therapy improves well-being. This was followed by cost (48.6\%), information from other patients ( $48.2 \%)$, proof that the therapy could cure cancer $(39.5 \%)$ and time needed to receive the therapy $(21.3 \%)$. Differences between TBCC and CIS responses were insignificant. In addition, information seekers wanted information that is current (66.9\%), explains how the therapy works $(63.5 \%)$, is easy to understand (58.9\%), is scientifically tested $(55.8 \%)$, is specific $(41.5 \%)$ and provides a range of information sources (47.1\%).

In written comments, respondents expressed interest in CT information on a variety of other topics. One respondent wanted information about a specific cancer type: "There is so much cancer research, but no one seems to know much about bladder cancer; no support groups, etc. You're on your own. The Centre for Integrated Healing [a centre in Vancouver, British Columbia that takes a holistic, healing approach to cancer care] is all the support we get." Or about preventing recurrence: "I would be interested in knowing if there is more therapy I should take even though I have been clean for $51 / 2$ years. ... Is there a way to help re-occurrence [sic] through complementary therapy?" The alleviation of the side effects of conventional treatments interested several respondents: "If complementary therapies help to alleviate side effects and protect healthy cells and tissues, it would be so beneficial to us undergoing chemo treatment."

\section{Used versus preferred sources for CT information}

Of those who sought CT information, there were marked differences between the people from whom the respondents actually obtained information and their preferred informants (Table 6). Although health professionals such as physicians were often the preferred information source, they were seldom used, and whereas friends or relatives were the most frequently used sources of information, they were not the preferred sources. This was also the case for respondents who were asked where they got the CT information they sought. Even though the Internet, health newsletters and books were used often, the respondents would have preferred to go to conventional cancer centres. 
TABLE 1

Demographic and disease characteristics of TBCC and CIS respondents

\begin{tabular}{|c|c|c|c|}
\hline Characteristic & $\begin{array}{c}\text { ТВСС } \\
n=404\end{array}$ & $\begin{array}{c}\text { CIS } \\
\mathbf{n}=303\end{array}$ & $p$-value \\
\hline Female (\%) & 39.0 & 77.9 & $<0.001$ \\
\hline Age range (mean) & 18 to $91(60.0)$ & 25 to 88 (57.3) & 0.007 \\
\hline \multicolumn{4}{|l|}{ Education (\%) } \\
\hline High school or less & 37.6 & 39.9 & 0.561 \\
\hline More than high school & 62.4 & 60.1 & 0.491 \\
\hline Years since diagnosis (range, mean) & $<1$ to 23 (3.5) & $<1$ to $29(2.1)$ & $<0.001$ \\
\hline \multirow[t]{4}{*}{ Years $(\%)$} & 2003 to 200471.8 & 2003 to 200438.6 & \\
\hline & 2001 to 20029.8 & 2001 to 200225.7 & \\
\hline & 1999 to $2000 \quad 5.8$ & 1999 to 200016.7 & \\
\hline & $<199912.5$ & $<199918.9$ & \\
\hline \multicolumn{4}{|l|}{ Types of cancer \% (top three) } \\
\hline Breast & 17.1 & 42.9 & $<0.001$ \\
\hline Colorectal & 7.9 & 5.9 & 0.309 \\
\hline Genitourinary & 24.5 & 10.6 & $<0.001$ \\
\hline \multicolumn{4}{|c|}{ Treatment history (\%) (previously or currently received) } \\
\hline Surgery & 42.8 & 61.7 & $<0.001$ \\
\hline Radiation therapy & 38.6 & 38.0 & 0.858 \\
\hline Chemotherapy & 29.5 & 44.2 & $<0.001$ \\
\hline Hormone therapy & 21.5 & 16.2 & $<0.001$ \\
\hline
\end{tabular}

TABLE 2

Percentage of TBCC and CIS respondents using complementary therapies (CTs)

\begin{tabular}{|c|c|c|c|}
\hline CT use & $\begin{array}{c}\text { ТВСC } \\
\mathrm{n}=\mathbf{4 0 4}\end{array}$ & $\begin{array}{c}\text { CIS } \\
n=303\end{array}$ & $p$-value \\
\hline Prior to cancer diagnosis & 21.5 & 34.7 & $<0.001$ \\
\hline Since cancer diagnosis & 30.4 & 36.3 & 0.101 \\
\hline
\end{tabular}

TABLE 3

Categories of complementary therapies currently used by TBCC and CIS respondents (\% of respondents)

\begin{tabular}{|c|c|c|c|c|}
\hline CT categories & Examples & $\begin{array}{c}\text { TBCC } \\
\mathrm{n}=94\end{array}$ & $\begin{array}{c}\text { CIS } \\
n=103\end{array}$ & $p$-value \\
\hline Herbs and supplements & Aloe vera, essiac, saw palmetto, flax & 44.7 & 28.2 & 0.016 \\
\hline Mind-body therapies & $\begin{array}{l}\text { Meditation, hypnosis, support groups, relaxation, } \\
\text { visualization/imagery }\end{array}$ & 31.9 & 40.8 & 0.129 \\
\hline Energy therapies & $\begin{array}{l}\text { Acupuncture, homeopathy, Chinese and ayurvedic medicine, } \\
\text { exercise, Tai Chi, therapeutic touch, yoga }\end{array}$ & 31.9 & 28.2 & 0.678 \\
\hline Vitamins and minerals & Amino acids, iron, vitamins A, B, C & 16.0 & 23.3 & 0.184 \\
\hline Physical therapies & Chiropractic, massage & 14.9 & 11.7 & 0.524 \\
\hline Special diets & Naturopathy, juicing diets, Gerson therapy & 11.7 & 22.3 & 0.045 \\
\hline Extracts and concentrates & Hydrogen peroxide, lycopene, laetrile & 7.4 & 8.7 & 0.722 \\
\hline Spiritual therapies & Prayer, faith healing and other spiritual rituals & 2.1 & 5.8 & 0.184 \\
\hline
\end{tabular}


TABLE 4

Reasons for using complementary therapies (\% of respondents)

\begin{tabular}{|c|c|c|c|}
\hline Reasons for CT use & $\begin{array}{c}\text { ТВСС } \\
\mathbf{n}=\mathbf{1 2 3}\end{array}$ & $\begin{array}{c}\text { CIS } \\
n=110\end{array}$ & $p$-value \\
\hline To improve health & 82.1 & 74.5 & 0.160 \\
\hline To strengthen immune system & 73.1 & 68.2 & 0.403 \\
\hline To give hope & 42.0 & 45.5 & 0.539 \\
\hline To supplement cancer treatments provided by doctor & 33.3 & 40.9 & 0.232 \\
\hline To ease side effects of therapy & 29.4 & 39.1 & 0.148 \\
\hline To cure cancer & 23.5 & 43.6 & 0.002 \\
\hline To relieve symptoms & 25.2 & 37.3 & 0.064 \\
\hline
\end{tabular}

TABLE 5

Percentage of TBCC and CIS respondents who had sought CT information by gender, age and previous CT use

\begin{tabular}{llrr}
\hline Characteristics & & TBCC & \multicolumn{1}{c}{ CIS } \\
& Male & 32.1 & $\mathbf{n}=\mathbf{3 0 3}$ \\
\hline Gender & Female & 41.7 & 25.4 \\
& $p$-value & 0.052 & 41.1 \\
& $\leq 50$ years & 43.8 & 0.022 \\
\hline Age & $>50$ years & 32.9 & 51.8 \\
& $p$-value & 0.053 & 31.9 \\
& Yes & 69.4 & 0.001 \\
\hline Previous CT use & No & 26.8 & 61.5 \\
& $p$-value & $<0.001$ & 25.1 \\
& & & $<0.001$ \\
\hline
\end{tabular}

\section{Use of evidence}

For the majority of information seekers (i.e. $60.5 \%$ ), evidence or proof that a complementary therapy works meant that there was scientific research to prove its effectiveness; however, if a scientific report stated that the CT which a respondent was using was ineffective, $47.9 \%$ in the TBCC sample and $33.6 \%$ in the CIS sample ( $p=$ 0.007) would continue to use it. Evidence that a CT works could also mean that the information came from a trusted source $(51.6 \%)$; the CT worked for others who used it (50.4\%); it was "my doctor's recommendation" $(27.0 \%)$; and "my gut feeling” (17.7\%). The two groups differed significantly with respect to "personal experience has proven that it works" (TBCC sample, $47 \%$ versus CIS sample, $26.4 \%$ ).

Some respondents strongly endorsed the need for scientific evidence in their comments. As one person said, "I would like to see independent bodies such as university studies giving credibility to alternative treatment." Others expressed concern with the lack of evidence-based information and the possible consequences: "I have been to a naturopath-not specifically for cancer treatment-but am always sceptical, as there is not much proven about these herbs and maybe they could do more harm than good." Several respondents were interested in patient testimonials or "softer" evidence, for example, "I would like to discuss the possibility of using complementary therapy with someone who has had prostate cancer and who used that therapy" and, "I hope to read many testimonials on how such treatment has improved the life and health of cancer patients, and even cured them. Surely all these people cannot be biased." However, others are interested in both types of evidence and take responsibility for their treatment decision, for example, "Mostly, I want to hear from the scientific community if there are any dangers in using a particular therapy. Then I want to hear from people who have tried it-patients and practitioners. What is their personal experience? Then I'd still weigh the cost to me (i.e. time and money) and make my own decision."

\section{Communication with physicians about CT use}

A large percentage of CT users (i.e. $60.7 \%$ in the TBCC group and $67 \%$ in the CIS group; $p=0.609$ ) reported having told their doctors about their CT use. Of the combined samples, $30.3 \%$ of users did not inform their doctors, and the remaining $6.0 \%$ indicated that they would like to tell, but felt they could not do so. Of the CT users who told their doctors ( $\mathrm{n}=147$ ), $18.2 \%$ of users reported that their doctors were very supportive and $43.2 \%$ of them had somewhat supportive doctors. Almost nine per cent of respondents (i.e. 8.8\%) reported having both doctors who were 
TABLE 6

CT information sources identified, used and preferred by TBCC and CIS respondents (\% of respondents)

\begin{tabular}{|c|c|c|c|c|}
\hline \multirow[t]{2}{*}{ CT information source } & \multicolumn{2}{|c|}{$\begin{array}{c}\text { TBCC } \\
n=144\end{array}$} & \multicolumn{2}{|c|}{$\begin{array}{c}\text { CIS } \\
n=112\end{array}$} \\
\hline & Used & Preferred & Used & Preferred \\
\hline Physician & 13.6 & 76.5 & 13.4 & 75.7 \\
\hline Patient/survivor & 22.1 & 50.7 & 40.2 & 58.6 \\
\hline Complementary practitioner & 32.9 & 50 & 36.6 & 47.7 \\
\hline Nurse & 10.7 & 23.5 & 15.2 & 20.7 \\
\hline Friend/relative & 61.4 & 17.6 & 58.9 & 16.2 \\
\hline Counsellor/psychologist & 3.6 & 6.6 & 9.8 & 18 \\
\hline Health food store employee & 17.9 & 5.9 & 24.1 & 8.1 \\
\hline Health newsletters & 40.7 & 41.9 & 50.5 & 38.4 \\
\hline Health organizations & 12.9 & 33.1 & 28.4 & 38.4 \\
\hline Books/library & 39.3 & 29.4 & 52.3 & 30.4 \\
\hline Scientific journals & 14.3 & 31.6 & 18.3 & 24.1 \\
\hline Telephone cancer information services $\dagger$ & 41.1 & 24.1 & 49.7 & \\
\hline Magazines/newspapers & 25 & 17.6 & 30.3 & 13.4 \\
\hline Television & 6.4 & 5.9 & 12.8 & 7.1 \\
\hline
\end{tabular}

"Telephone cancer information services" this response option was included only on the CIS questionnaire

supportive as well as doctors who were not, and $10.8 \%$ of users had unsupportive doctors. The remaining $18.9 \%$ of CT users did not know whether their doctors were supportive.

In their comments on the questionnaires, several respondents discussed the need for physicians to have more knowledge about CTs and to be willing to discuss CT with patients early in the treatment. As one respondent said, "It is useless to tell your oncologist about herbal remedies. He has no knowledge of them, nor time to research them, so he also [sic] dismisses them as inconsequential or harmful, with no evidence to support his view." Another user stated, "Cancer patients need more information about complementary therapy as soon as they are diagnosed with cancer, and my doctor would be the best person to do this."

\section{Discussion}

For this study, we recruited two consecutive samples of cancer patients from two different populations. The TBCC and CIS samples differed in terms of the percentage of females (which impacts on type of cancer and treatment statistics), time since diagnosis and previous CT use. With a few exceptions, we found that the data are remarkably similar regarding information seeking, and used and preferred information sources, even though we were dealing with a very unique sample of CIS individuals who actively seek cancer-related information and who may be different from other information seekers, in terms of beliefs and attitudes.

The decision to use CTs is highly personal and complex.22 The reasons participants in the current study stated for using CTs reiterate those reported in the literature. ${ }^{3,26-28}$ In most cases, respondents looked to CTs to improve their health, strengthen their immune system or enhance their wellbeing and quality of life. Physicians, other patients, scientific research or personal intuition may, independently or jointly, influence a patient's decision to use CTs. Information seeking may bring several benefits, such as increased involvement in making treatment decisions, improved ability to cope after diagnosis and treatment, reduced anxiety and mood disturbances, and improved communication with family members. ${ }^{11}$ It is therefore important that patients are supported in their search for information and that they have access to accurate, comprehensive information.

Perhaps the most intriguing finding is the difference between used and preferred sources of CT information. In both samples, patients preferred information from conventional health care providers (i.e. physicians, pharmacists and nurses) and conventional cancer centres; however, 
TABLE 7

\section{Resource books and Web sites}

\section{Books}

Ernst E, Pittler MH, Wider B, Boddy K. Oxford handbook of complementary medicine. Oxford: Oxford University Press, 2008. Oncology: p. 342-8. Evidence for all treatments is rated.

Rakel D, Integrative medicine, 2nd ed. Philadelphia: Saunders, and imprint of Elsevier Inc. 2007. Section 13: Integrative oncology - an overview: p. 809-99. Evidence for all treatments is rated.

Ernst E, Pittler MH, Wider B, editors. The desktop guide to complementary and alternative medicine: an evidence-based approach, 2nd ed. Philadelphia: Mosby, an imprint of Elsevier Limited, 2006. Cancer: p. 80-8. Evidence for all treatments is rated.

Kligler B, Lee R. Integrative medicine: principles for practice. New York: McGraw-Hill, 2004. Chapter 23: Integrative approach to oncology: p. 535-49.

Kohatsu W. Complementary and alternative medicine secrets: Q \& As about integrating CAM therapies into clinical practice. Philadelphia: Hanley \& Belfus, Inc. 2002. Chapter 55: Approach to specific cancers: p. 377-88.

\begin{tabular}{l} 
Web sites \\
\hline The University of Texas MD Anderson Cancer Center Complementary/Integrative Medicine \\
Education Resources: http://www.mdanderson.org/departments/cimer \\
Memorial Sloan Kettering Cancer Center: http://www.mskcc.org/mskcc/html/44.cfm \\
CAMline: http://www.camline.ca/ \\
Center for Health and Healing, a service of Beth Israel Medical Center in New York: \\
http://www.healthandhealingny.org/ \\
National Center for Complementary and Alternative Medicine (NCCAM): http://nccam.nih.gov/health/ \\
Natural Medicines Comprehensive Database - Clinical Management Series: \\
http://www.naturaldatabase.com/(S(st2arzb2hbi2v355rtipno2p))/nd/ClinicalMngt.aspx?cs=\&s=ND \\
Natural Medicines Comprehensive Database: http://www.naturaldatabase.com \\
Natural Standard Database: http://www.naturalstandard.com/
\end{tabular}

there was a large gap between preferred and actual sources used. The preference for information from their doctors has been reported in earlier studies, ${ }^{11}$ yet relatively few patients asked their doctors for information. This may stem from a reluctance to use valuable resources (e.g. doctor's time) when patients perceive others need these resources more, or they may question a physician's willingness to talk about CTs or his or her knowledge of this subject. Consequently, these patients may find it easier to obtain information from family or friends, ${ }^{21}$ the Internet, ${ }^{14}$ health newsletters, books and the library. Unfortunately, health information from Web sites often contains conflicting, wrong or incomplete information ${ }^{18,19}$ regarding the safety or efficacy of $\mathrm{CTs},{ }^{17}$ and family or friends may not have the necessary knowledge to provide evidence-based information.

Given study participants' use of CTs and their preferences for current, scientifically based and easily understood information about this subject, health care providers and conventional cancer centres have an important role to play in disseminating information. ${ }^{29}$ It is especially important that health care providers bridge the gap between preferred information sources and those used and open up discussion about this matter with their patients, because so many patients do not report CT use to their physicians. ${ }^{18}$ Compared to the literature, ${ }^{30-31}$ a fairly large number of participants in this study reported their CT use to their physicians; however, over a third did not. Uncertainty regarding their physician's support of their CT use or, as reported in previous research, a feeling of discomfort in discussing CT use with their conventional health care providers ${ }^{20}$ may result in patients seeking opportunities to discuss and gain support for CT use elsewhere.

Since patients may have already collected CT information prior to talking with a health care provider (e.g. obtaining basic information from the Internet), ${ }^{14}$ it has been suggested that as cancer information seekers become more skilled at finding information, their needs may shift from seeking information to requiring assistance with interpreting information. ${ }^{32,33}$ Although the need for health care providers to be cognizant of available CT information sources has been previously identified, ${ }^{29,30,32,34}$ health care providers are also challenged to find valid and comprehensive CT information that they can discuss and share with their patients. Since changing or conflicting information regarding $\mathrm{CTs}$ can be confusing for both health care providers and patients seeking information, ${ }^{35}$ current, comprehensive information sources would be helpful. CIS telephone helplines may be able to assist health care providers in developing the skills to communicate about CTs, as well as provide them with resources they can use to assist patients in decision making. Information that would be available to both patients and health care providers could include how to choose a complementary practitioner or natural health products. A guide such as "Complementary Healthcare: A Guide for Patients" may be a helpful start. ${ }^{36}$ It includes helpful information on where to find CT practitioners and what questions to ask of them. High-quality, evidence-based CT information is increasingly available; Table 7 lists some available resources. Furthermore, the development of the relatively new discipline of integrative oncology reflects a shift in focus from biomedical cancer treatment to the more comprehensive concept of cancer care. Integrative oncology has been defined as "the ability to integrate the best of complementary and mainstream care using a multidisciplinary approach, combining the best of mainstream cancer care and rational, data-based, adjunctive CTs." ${ }^{37}$ This development will most likely lead to further development of and guidelines regarding CTs.

The results also showed that patients rely on or trust information sources of nonscientific, research-based evidence. Although the importance of scientific evidence is without question, the literature increasingly points out that non-scientific evidence factors are important to consider as well. Sackett et al. have defined evidence-based 
medicine as "the integration of the best research evidence with clinical expertise and patient values." 38 This definition highlights that clinical expertise, partially based on empirical observation, may provide important information above and beyond what can be learned from clinical trials. In addition, it highlights that the patient has important knowledge which is unavailable to the health care provider. Whereas clinical expertise and patient values are limited by their subjective nature, scientific evidence is limited in its bias towards "objectivity," attempt to control and discounting of important subjective factors. Scientific evidence, clinical expertise and patient values combined will greatly contribute to optimal evidence-based patient care.

This study raises important issues regarding patients' need for and use of CT information, despite being limited due to its cross-sectional nature, the general nature of the questions in the questionnaire and two very specific samples that do not allow generalizations to the larger population of CT information seekers. Such information may be helpful for patients, in further clarifying their questions, and for health care providers, in understanding patients' inquiries and learning how to address them.

\section{Conclusion}

Cancer patients would prefer to receive CT information from conventional health professionals and cancer centres. They also want this information to be cancer-specific and comprehensive. Cancer information services can play a valuable role in the provision of CT information to both patients and conventional health care professionals. Patients seek information from a number of sources and evaluate the trustworthiness and validity of that information in different, sometimes conflicting, ways. Therefore, it is important to acknowledge that patients may use information based on scientific research as well as "softer" evidence, such as patient testimonials. The creation of a supportive care environment through CT information provision may help address some of the concerns of cancer patients and alleviate some of the stress that may have been caused by the cancer diagnosis.

\section{Acknowledgements}

Support for this project was provided by the Alberta Heritage Foundation for Medical Research. We want to thank the Outpatient Clinic of the Tom Baker Cancer Centre and the Cancer Information Service of the Canadian Cancer Society for the cooperation of its staff and its support of this project.

\section{References}

1. NCCAM: National Center for Complementary and Alternative Medicine. Expanding Horizons of Health Care. What is CAM? [Internet]. National Institutes of Health, Bethesda (MD) [cited 2008, Nov 25]. URL: http://nccam.nih.gov/health/ whatiscam/.

2. Ashikaga T, Bosompra K, O'Brien P, Nelson L. Use of complementary and alternative medicine by breast cancer patients: prevalence, patterns and communication with physicians. Support Care Cancer. 2002;10(7):542-48.

3. Eng J, Ramsum D, Verhoef M, Guns E, Davison J, Gallagher R. A population-based survey of complementary and alternative medicine use in men recently diagnosed with prostate cancer. Integr Cancer Ther. 2003;2(3):212-16.

4. Ernst E, Cassileth BR. The prevalence of complementary/alternative medicine in cancer: a systematic review. Cancer. 1998 Aug 15;83(4):777-82.

5. McKay DJ, Bentley JR, Grimshaw RN. Complementary and alternative medicine in gynaecologic oncology. J Obstet Gynaecol Can. 2005;27(6):562-68.

6. Richardson MA, Sanders T, Palmer JL, Greisinger A, Singletary SE. Complementary/ alternative medicine use in a comprehensive cancer center and the implications for oncology. J Clin Oncol. 2000;18:2505-14.

7. Tough SC, Johnston DW, Verhoef MJ, Arthur K, Bryant H. Complementary and alternative medicine use among colorectal cancer patients in Alberta, Canada. Altern Ther Health Med. 2002;8(2):54-60,62.
8. Yates JS, Mustian KM, Morrow GR, et al. Prevalence of complementary and alternative medicine use in cancer patients during treatment. Support Care Cancer. 2005;13(10):806-11 .

9. Mitchell SA, Beck SL, Hood LE, Moore K, Tanner ER. Putting evidence into practice: evidence-based interventions for fatigue during and following cancer and its treatment. Clin J Oncol Nurs. 2007 Feb; 11(1):99-113 .

10. Tipton JM, McDaniel RW, Barbour L, et al. Putting evidence into practice: evidencebased interventions to prevent, manage, and treat chemotherapy-induced nausea and vomiting. Clin J Oncol Nurs. 2007 Feb;11(1):69-78.

11. Rutten LJ, Arora NK, Bakos AD, Aziz N, Rowland J. Information needs and sources of information among cancer patients: a systematic review of research (1980-2003). Patient Educ Couns. 2005 Jun;57(3):250-61.

12. Basch EM, Thaler HT, Shi W, Yakren S, Schrag D. Use of information resources by patients with cancer and their companions. Cancer. 2004 Jun1;100(11):2476-83.

13. Carlsson M. Cancer patients seeking information from sources outside the health care system. Support Care Cancer. 2000 Nov; 8(6):453-57.

14. Hardyman R, Hardy P, Brodie J, Stephens R. It's good to talk: comparison of a telephone helpline and website for cancer information. Patient Educ Couns. 2005 Jun;57(3):315-20.

15. Bott J. An analysis of paper-based sources of information on complementary therapies. Complement Ther Clin Pract. 2007 Feb;13(1):53-62.

16. Chen X, Siu L. Impact of the media and the Internet on oncology: Survey of cancer patients and oncologists in Canada. J Clin Oncol. 2001 Dec 1;19(23):4291-97.

17. Walji M, Sagaram S, Sagaram D, MericBernstam F, Johnson C, Mirza NQ, Bernstam EV. Efficacy of quality criteria to identify potentially harmful information: a cross-sectional survey of complementary 
and alternative medicine web sites. J Med Internet Res. 2004 Jun 29;6(2):e21.

18. Molassiotis A, Xu M. Quality and safety issues of web-based information about herbal medicines in the treatment of cancer. Complement Ther Med. 2004 Dec;12(4):217-27.

19. Schmidt K, Ernst E. Assessing websites on complementary and alternative medicine for cancer. Ann Oncol 2004;15(5):733-42.

20. Washburn A, Thomsen C. Cancer patients and CAM: exploring information needs. Abstract. Focus Altern Complement Ther. 2003;8(4):552.

21. Leydon GM, Boulton M, Moynihan C, et al. Cancer patients' information needs and information seeking behaviour: in depth interview study. BMJ. 2000 Apr 1; 320(7239):909-13.

22. Balneaves LG, Bottorff JL, Truant T, Davison BJ. Information needs of breast and prostate cancer patients using complementary therapies: a pilot study. Abstract. Can Oncol Nurs J. 2005;15(1):42.

23. Maxwell JA. Qualitative research design: an interactive approach. Thousand Oaks (CA): Sage Publications; 1996:96-98.

24. Morse JM, Richards L. Readme first for a user's guide to qualitative methods. Thousand Oaks (CA): Sage Publications; 2002:149-150.

25. Eng JL, Monkman DA, Verhoef MJ, Ramsum DL, Bradbury J. Canadian Cancer Society Information Services: lessons learned about complementary medicine information needs. Chronic Dis Can. 2001; 22(3-4):102-7.

26. Molassiotis A, Fernadez-Ortega P, Pud D, et al. Use of complementary and alternative medicine in cancer patients: a European survey. Ann Oncol. 2005 Apr;16(4):655-63.

27. Vapiwala N, Mick R, Hampshire MK, Metz JM, DeNittis AS. Patient initiation of complementary and alternative medical therapies (CAM) following cancer diagnosis. Cancer J. 2006 Nov-Dec;12:467-74.
28. Correa-Velez I, Clavarino A, Eastwood H. Surviving, relieving, repairing, and boosting up: reasons for using complementary/ alternative medicine among patients with advanced cancer: a thematic analysis. J Palliat Med. 2005 Oct;8(5):953-61.

29. Mackenzie G, Parkinson M, Lakhani A, Pannekoek H. Issues that influence patient/ physician discussion of complementary therapies. Patient Educ Couns. 1999 Oct; 38(2):155-59.

30. Diaz JA, Griffith RA, Ng JJ, Reinert SE, Friedmann PD, Moulton AW. Patients' use of the Internet for medical information. J Gen Intern Med. 2002 Mar;17(3):180-85.

31. Cohen L, Cohen MH, Kirkwood C, Russell NC. Discussing complementary therapies in an oncology setting. J Soc Integr Oncol. 2007 Winter;5(1):18-24.

32. Walji M, Sagaram S, Meric-Bernstam F, Johnson CW, Bernstam EV. Searching for cancer-related information online: unintended retrieval of complementary and alternative medicine information. Int J Med Inform. 2005 Aug;74(7-8):685-93.

33. Bright MA, Fleisher L, Thomsen C, Morra ME, Marcus A, Gehring W. Exploring e-health usage and interest among cancer information service users: the need for personalized interactions and multiple channels remains. J Health Commun. 10 Suppl. 2005;1:35-52.

34. Lee CO. Communicating facts and knowledge in cancer complementary and alternative medicine. Semin Oncol Nurs. 2005 Aug;21(3):201-14.

35. Ernst E, Pittler MH, Wider B, Boddy K. Complementary/alternative medicine for supportive cancer care: development of the evidence-base. Support Care Cancer. 2007 May;15(5):565-68.

36. Pinder M, Pedro L, Theodorou G, Treacy K. Complementary healthcare: a guide for patients. [Internet]. London: The Prince's Foundation for Integrated Health; 2007 [cited 2008, Nov 25]. URL: http://www.fih. org.uk/document.rm?id $=19$
37. Deng GE, Cassileth BR, Cohen L, et al. Integrative oncology practice guidelines. J Soc Integr Oncol. 2007 Spring; 5(2):65-84.

38. Sackett DL, Straus SE, Richardson WS, et al. Evidence-based medicine: how to practice and teach EBM. 2nd ed. London: Churchill Livingstone; 2000:1. 